\title{
The Effect of Recruitment, Competence, Motivation and Organization Culture On Job Satisfaction and Performance of Government Employees In Indonesia
}

\author{
Sosiawan Ma'mun \\ STKIP Pembangunan Indonesia \\ Makassar, Indonesia \\ sosiawan_mamun@yahoo.co.id
}

Sulfaidah

STKIP Pembangunan Indonesia

Makassar, Indonesia

\author{
Muallim \\ STKIP Pembangunan Indonesia \\ Makassar, Indonesia
}

\author{
Yahya \\ STKIP Pembangunan Indonesia \\ Makassar, Indonesia
}

\begin{abstract}
The objectives of this research were to analyze: 1) the effect of recruitment, competence, motivation and organization culture on job satisfaction of government employees in Indonesia; 2) the effect of recruitment, competence, motivation and organization culture on performance of government employees in Indonesia; and 3) the effect of job satisfaction on performance of government employees in Indonesia. The research was conducted at Indonesian Government Office. The population was 2.688 government employees. The sample consisted of 348 respondents, yet 250 respondents who returned the questionnaire were subsequently sampled for analysis using structural equation model with the use of AMOS ver.18. The result showed that the competence has a negative and significant effect on job satisfaction. It indicates that the employees' competence needs to be improved, so that employees are satisfied with their work. Organizational culture has a positive and insignificant effect on job satisfaction. Moreover, competence has a positive and insignificant effect on performance. Lastly, motivation gives a negative and insignificant effect on employees' performance.
\end{abstract}

Keywords-recruitment; competence; motivation; organization culture; job satisfaction; government employees

\section{INTRODUCTION}

Management is a major force in an organization for human resource development. Through a good management function, an organization is capable to be more advanced and modern. Understanding the importance of organizational management is the key in achieving the goals [1]. The implementation of the Directorate in a government agency as a non-profit organization has not been practice optimally.

The indication of dissatisfaction felt by some employees may affect their performance. The attainment of work realization does not reach the specified target. Employers often complain and reprimand their subordinates who have low performance [2]. Employee performance evaluation decreases in quantity from the number of work completed, low quality of work, unfinished work (no efficiency), less useful work completion (no effectiveness), and low adherence (devotion). It is caused by the less selective recruitment, employees' low competence, less motivated and fragile organization culture [3]

Low performance also occurs as a consequence of the recruitment, low competence, low motivation, and low organization culture possessed by the employees. The low level of individual job satisfaction is obviously seen from the dissatisfaction of employees toward their work, the unwillingness of taking the job risk, poor work, and underperforming tasks. This unsatisfied feeling and complants exist due to the lack of appreciation for the work, and the rarely given work responsibility. These are the forms of unsatisfied employees.

Certainly, employees should be able to show their personal satisfaction. Parmenter stated that satisfaction is distinguished by the expression of satisfied and unsatisfied feeling [4]. Assessing one's satisfaction can be seen from their contented expression about their interesting job, work challenge, the opportunity for achievement, and reward on work responsibilities.

Based on the description above, the problem to be solved is to analyze the effect of recruitment, competence, motivation, and organization culture toward satisfaction. It is also to analyze the effect of those factors toward performance, and to analyze the effect of satisfaction toward performance.

\section{RESEARCH METHOD}

The research approach is designed to address formulated problems, to achieve objectives, and to examine hypothesis. The research design is a structured investigation so that researcher can obtain answers to the questions. 
The study was scheduled in two months starting from April to May 2013. The study was conducted in the Indonesian government. The data were quantitative and consisted of primary and secondary data. The population in this study was 2.688 officials in Indonesia. The sample is the set of sampling unit chosen from a sampling design. Cooper, Schindler and Sun proposes that sample is the part of selected population which can represent the population [5]. Using Slovin's formula, there were 348 respondents applied in this research.

The technique of data analysis used in this study to explain the phenomena is the statistic descriptive technique analysis and Structural Equation Modeling (SEM) analysis.

The formed measurement model was determined to test the suitability of the model. There are some suitability index models that can be used to measure whether or not a model is fit: (a) Chi-Square Statistic (CSS); (b) The Root Mean Square Error of Approximation (RMSEA); (c) Goodness of Fit Indices (GFI); (d) Adjusted Goodness of Fit Indices (AGFI); (e) Comparative Fit Indices (CFI).

Validity is a measure of validity degree or instrument validity. An instrument is said to be valid if it can reveal data from the properly studied variables. The validity degree of the instrument indicates the extent of data collected, not stored from the intended validity description.

\section{RESULT AND DISCUSSION}

Based on the method for determining value in a model, the first model testing variables are grouped into exogenous variables and endogenous variables. The model evaluation shows, from the eight criteria goodness of fit indices, chisquare value is still large, and there are some criteria which do not conform to the specified cut-off value. Thus model modification is done through correlating between errors indicators based on the modification indices. The result of the analysis is shown below:

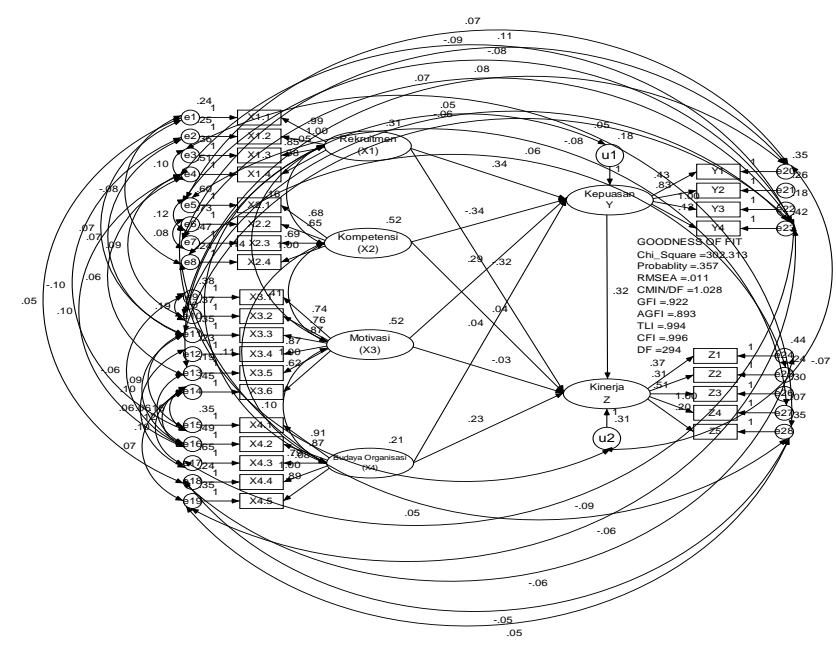

Fig. 1. Measurement of Model Variable relations
The result of the model test presented in figure 2 above is evaluated based on goodness of fit. It is shown on table 1 below along with the criteria of the model as well as the critical values which are suitable for the data.

TABLE I. EVALUATION CRITERIA FOR GOODNESS OF FIT INDICES OVERALL MODEL

\begin{tabular}{|l|l|l|l|}
\hline \multicolumn{1}{|c|}{$\begin{array}{c}\text { Goodness of fit } \\
\text { index }\end{array}$} & Cut-off Value & \multicolumn{1}{|c|}{ Model result $^{\text {a }}$} & \multicolumn{1}{|c|}{ Note } \\
\hline Chi_Square & Expected to be & $302.313(0.05: 294$ & Good \\
Probability & low & $=334.9898$ & Good \\
CMIN/DF & $\geq 0.05$ & 0.357 & Good \\
RMSEA & $\leq 2.00$ & 1.028 & Good \\
GFI & $\leq 0.08$ & 0.011 & Good \\
AGFI & $\geq 0.90$ & 0.922 & Poor \\
TLI & $\geq 0.90$ & 0.893 & Good \\
CFI & $\geq 0.94$ & 0.994 & Good \\
\hline
\end{tabular}

The model evaluation shows the eight criteria of goodness of fit indices which match the cut-off value criteria. The model can be considered to be appropriate with the goodness of fit indices criteria to be analyzed.

Based on the proposed empirical model in this research, the hypothesis can be tested using coefficient test on the structural equation. Table 2 is the hypothesis test by looking at the $p$-value. If the score of $p$-value is lower than 0.05 , the variable relations are significant. It can also explain the direct effect which means that there is a direct positive effect on the variables. On the other hand, the indirect effect means that there is an indirect positive effect between variables. The total effect is the accumulation of direct effect and indirect effect. The test result presented in the following Table 2.

From the whole models, there are six models which have a significant effect. Table 2 can be interpreted as follows:

- Recruitment has a positive and significant effect on job satisfaction with $\mathrm{p}=0.000<0.05$ and 0.394 direct effect value.

- Competence has a negative and significant effect on job satisfaction with $\mathrm{p}=0.014<0.05$ and -0.508 direct effect value.

- Motivation has a negative and significant effect on job satisfaction with $\mathrm{p}=0.016<0.05$, and 0.444 direct effect value.

- Organization culture has a positive and insignificant effect on job satisfaction with $\mathrm{p}=0.710>0.05$ and 0.038 direct value.

- Recruitment has a negative and significant effect on performance with $\mathrm{p}=0.006<0.05$ and -0.303 direct effect value.

- Competence has a positive and insignificant on performance with $\mathrm{p}=0.810>0.05$ and 0.043 direct effect value.

- Motivation has a negative and insignificant effect on performance with $\mathrm{p}=0.813>0.05$ and -0.037 direct effect value. 
- Organization culture has a positive and significant effect on performance with $\mathrm{p}=0.047$ and 0.178 direct effect value.
- Job satisfaction has a positive and significant effect on performance with $\mathrm{p}=0.019<0.05$ and 0.259 direct effect value.

TABLE II. The Hypothesis Test OF DiRECT EFFECT, INDIRECT EFFECT, AND TotAl EFFECT

\begin{tabular}{|c|c|c|c|c|c|c|c|c|}
\hline \multirow{2}{*}{ HIP } & \multicolumn{3}{|c|}{ Variable } & \multicolumn{3}{|c|}{ Standardize } & \multirow{2}{*}{ P.Value } & \multirow{2}{*}{ Note } \\
\hline & Independent & Interdependent & Dependent & Direct & Indirect & Total & & \\
\hline 1 & Recruitment & Satisfaction & - & 0.394 & - & 0.394 & $* * *$ & Significant \\
\hline 2 & Competence & Satisfaction & - & -0.508 & - & -0.508 & 0.014 & Significant \\
\hline 3 & Motivation & Satisfaction & - & 0.444 & - & 0.444 & 0.016 & Significant \\
\hline 4 & Organization culture & Satisfaction & - & 0.038 & - & 0.038 & 0.710 & Insignificant \\
\hline 5 & Recruitment & Satisfaction & Performance & -0.303 & 0.102 & -0.201 & 0.006 & Insignificant \\
\hline 6 & Competence & Satisfaction & Performance & 0.043 & -0.132 & -0.088 & 0.810 & Insignificant \\
\hline 7 & Motivation & Satisfaction & Performance & -0.037 & 0.115 & -0.078 & 0.813 & Insignificant \\
\hline 8 & Organization culture & Satisfaction & Performance & 0.178 & 0.010 & 0.188 & 0.047 & Significant \\
\hline 9 & Satisfaction & Satisfaction & Performance & - & 0.259 & 0.259 & 0.019 & Significant \\
\hline
\end{tabular}

Indirectly, organization culture has a significant positive effect on performance through job satisfaction with $\mathrm{p}<0.05$ and 0.013 indirect effect value. The competence has an adverse effect on performance through job satisfaction and 0.132 indirect effect value which means that performance is determined by the competence applied by employees based on the perceived job satisfaction.

\section{CONCLUSION}

Recruitment has a positive and significant effect on employees' job satisfaction. Employees who have been through the recruitment show that they have been selected and feel satisfied with their job. Competence has a negative and significant effect on employees' job satisfaction. Competence possessed by the employees needs to be improved so that it can give effect to job satisfaction. Motivation has a positive and significant effect on employees' job satisfaction. If employees are motivated, they will be satisfied with their work. Organization culture has a positive and insignificant effect on employees' job satisfaction. Actualizing employees' habit on implementing organization culture has not been able to shape employees' job satisfaction.

\section{References}

[1] A. Som, "Innovative human resource management and corporate performance in the context of economic liberalization in India," Int. J. Hum. Resour. Manag., vol. 19, no. 7, pp. 1278-1297, 2008.

[2] D. J. Schleicher, J. D. Watt, and G. J. Greguras, "Reexamining the job satisfaction-performance relationship: the complexity of attitudes.," $J$. Appl. Psychol., vol. 89, no. 1, p. 165, 2004.

[3] C. D. Fisher, "Why do lay people believe that satisfaction and performance are correlated? Possible sources of a commonsense theory," J. Organ. Behav., vol. 24, no. 6, pp. 753-777, 2003.

[4] D. Parmenter, Key performance indicators: developing, implementing, and using winning KPIs. John Wiley \& Sons, 2015.

[5] D. R. Cooper, P. S. Schindler, and J. Sun, "Business research methods," 2003. 